\title{
The Application of Thermal Building Nano-Insulation Materials Based on the Diffusivity Characteristic of Polyurethane Nanocomposite
}

\author{
Norayuni Azizi and Kamal Yusoh
}

\begin{abstract}
The paper aims to study diffusivity measurement of polyurethane (PU) nanocomposite with incorporation of montmorillonite nanoclay cloisite B30 (B30) prepared by solution intercalation method using chloroform as a solvent. The mixed compositions based on PU/B30 were analyzed according to the following weight percentage using $0.5 \%, 1 \%$, $2 \%$ and $4 \%$ of montmorillonite nanoclay cloisite B30. The morphology of the samples was observed through Scanning Electron Microscopy (SEM) and Fourier Transform Infrared Spectrometer (FTIR). The observation of SEM showed PU/B30 is not miscible meanwhile FTIR revealed that the surface segregation of the montmorillonite nanoclay cloisite B30 had not affected in PU. Next, water permeability test was conducted using nitrogen gas with different pressures. The pristine PU shows the lowest time taken for both pressures and contrary to the PU nanocomposite. This is supported by water absorption test in which the PU nanocomposite absorbs more water rather than the pristine PU.
\end{abstract}

Index Terms-Polyurethane, insulation, mechanical characteristics, nanocomposite.

\section{INTRODUCTION}

Thermal insulation in building reduces the rate of heat transmission across these building elements, but nowadays, higher cost is needed to provide higher energy saving because of the thicker insulation has been applied [1]. So, the alternative way that has been chosen is by replacing polymer nanocomposite as the main component for thermal insulation materials. Polymer nanocomposite has gained much attention for development in many interests recently [2]. Thus, polymer nanocomposite leads to enhance the properties of polymer itself. There are several publications regarding to the incorporation of nanocomposite in polymeric matrixes in term of enhancing the polymer properties and builds a new product $[3,4]$. For instance, the improvement has been found in mechanical, thermal, permeability and diffusivity manners [5]. Previously, many industries are aiming on microcomposite technology. As comparing the microcomposite and nanocomposite, nanocomposite is lower in size and provides more surface area for interfacial interaction [6]. Polyurethane is a

\footnotetext{
Manuscript received August 4, 2013; revised October 28, 2013. This work was supported in part by the Universiti Malaysia Pahang (UMP) for the Ministry of Higher Education Grant RDU100110 and RDU100345

Azizi N. and Yusoh K. are with the Faculty of Chemical and Natural Resources, Universiti Malaysia Pahang, 26300 Kuantan, Pahang. (e-mail: uny.norayuni@gmail.com; kamal@ump.edu.my).
}

thermoplastic polymer with unique properties as simultaneously it can be a thermoset polymer after the addition of cross-linking agent [7]. Moreover, PU has a good compatibility and a preferable mechanical property made it is one of the most versatile polymers for many different of application [8]. Basically, PU received much attention in thermal building insulation because this type of polymer can improve appearance and lifespan for coatings and has as well as low maintenance cost [9]. The objective of this study is to synthesize a very thin thermal building insulation material (TIM) using polyurethane-clay nanocomposite via solution intercalation method, besides characterize PU nanocomposite using SEM and FTIR and investigate the material by means of diffusivity properties.

\section{EXPERIMENTAL SECTION}

\section{A. Materials}

PU and Cloisite B30 was the main material in this research. PU (flash point; $400{ }^{\circ} \mathrm{C}$, density; $1.22 \mathrm{~g} / \mathrm{cm}^{3}$, tensile strength; $25 \mathrm{MPa}$, elongation at break; $750 \%$ ) was obtained from Innovative Pultrusion Sdn Bhd meanwhile Cloisite B30 (ignition temperature; $190{ }^{\circ} \mathrm{C}$, deflection temperature at $46 \mathrm{MPa} ; 96{ }^{\circ} \mathrm{C}$ decomposes at approximately $200{ }^{\circ} \mathrm{C}$, specific gravity; $1.9-2.1 \mathrm{~g} / \mathrm{cm}^{3}$ ) was obtained from Southern Clay Products Inc., USA. The chemical solution consumed was chloroform (molecular weight, Mw; 119.38 $\mathrm{g} / \mathrm{mol}$, CAS number; 67-66-3) which is used as solvent was obtained from Fischer Scientific (M) Sdn Bhd.

\section{B. Synthesis of $P U$ and PU Nanocomposite}

\section{1) Preparation of pristine $P U$}

Pellet forms of PU were dried in a dry oven at $80{ }^{\circ} \mathrm{C}$ for at least $3 \mathrm{~h}$. Two grams of PU was dissolved in chloroform solvent with $50 \mathrm{~mL}$ followed by the whole solution was magnetically stirred and heated at $80{ }^{\circ} \mathrm{C}$ for $5 \mathrm{~h}$ to form a well dissolved solution. Then, the solution was degassed and the solvent was removed at room temperature for $24 \mathrm{~h}$ and at last, an elastic and rubbery film was produced.

\section{2) Preparation of $P U$ Nanocomposite}

Pellet forms of PU and cloisite B30 were dried in a dry oven at $80{ }^{\circ} \mathrm{C}$ for at least $3 \mathrm{~h}$. The different series of B30 $(0.5 \%, 1 \%, 2 \%$ and $4 \%)$ were stirred vigorously in chloroform solvent with $50 \mathrm{~mL}$ for an hour. After that, PU pellet forms with according weight percentage $(99.5 \%$, $99 \%, 98 \%$ and $96 \%$ ) were added in the solution and stirred for $5 \mathrm{~h}$. At room temperature, the PU nanocomposite solutions were formed by casting in petri dishes and removed the solvent at room temperature for $24 \mathrm{~h}$. 


\section{3) Methodology}

The surface morphology and structure of the fabricated thin film and nanoclay were investigated by CARL ZEISS EVO Analytical Field Emission Scanning Electron Microscopy. The samples for SEM were coated with platinum using Pt coater and examined at an accelerating voltage of $15 \mathrm{kV}$. The water permeability was carried out based on the specification of ASTM D570 was conducted for water absorption test and the specimen was performed as round shape with diameter $80 \mathrm{~mm}$. All series of the samples were dried in a dry oven at $80{ }^{\circ} \mathrm{C}$ for $24 \mathrm{~h}$. Then, the samples were cooled in desiccators and instantaneously weighed every sample. The first weights of the samples were symbolized as $W_{0}$. Afterwards, the samples were wholly immersed in deionized water for $24 \mathrm{~h}$ at room temperature. Subsequently, removed water on the surface of samples with clean dry cloth and instantly, all the samples were weighed to get final weight, $W_{1}$. The formula $\left(W_{1}-\right.$ $\left.W_{0}\right) / W_{0}$ was used to calculate the percentage of weight increase of every sample to the nearest $0.01 \%$.

\section{RESULT AND DisCUSSION}

\section{A. Morphology}

SEM is employed to study how the B30 dispersed in the PU matrixes. Fig. 1(a) shows the fracture of nanofiller which is B30 particles in nano-scale sized. For the pristine PU in Fig. 1(b), there is some PU fracture that is not dissolves well in chloroform. For the Fig. 1(c), (d), (e) and (f), the micrographs of the samples show there are so many agglomerates form. This is due to the nanofiller is not well dispersed while in the stirring stage and assembled at a certain area. Moreover, in the micrographs can be seen that the dispersion might be intercalated or exfoliated due to the agglomerates formed in the samples. The nanofiller blocked the polymeric molecules from entering the silicate layered by enlarging the molecular spacing. This is supported by the poor interaction between matrixes and fillers will result bad manners despite of by adding fillers will enhance the properties of the polymer [10].

The other morphology analysis that has been conducted is FTIR shown in Fig. 2. In the figure, there are no obvious different between all the samples which mean that all the peaks found in the figure have identical with each sample. Thus, there are no chemical reactions involved between the polymer matrixes and the nanofiller as well as B30 has not affected the polyurethane segmented structure because FTIR did not indicate any change in PU. All the samples inhibit the same infrared spectra peaks at $2917 \mathrm{~cm}^{-1}$ indicates that the $-\mathrm{CH}$ stretching of $-\mathrm{CH}_{3}[11]-[13]$.

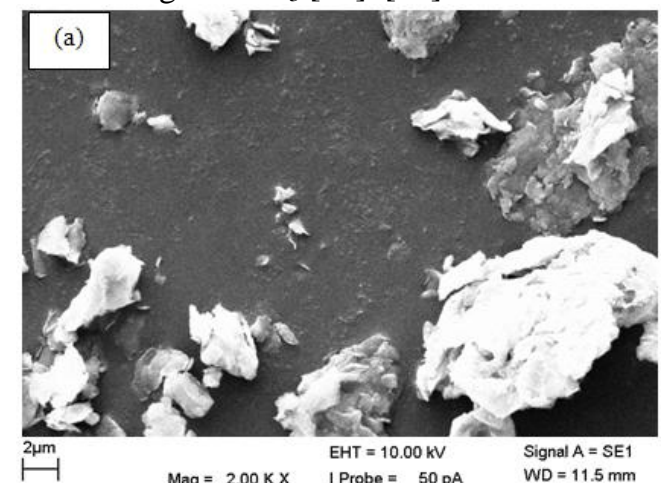

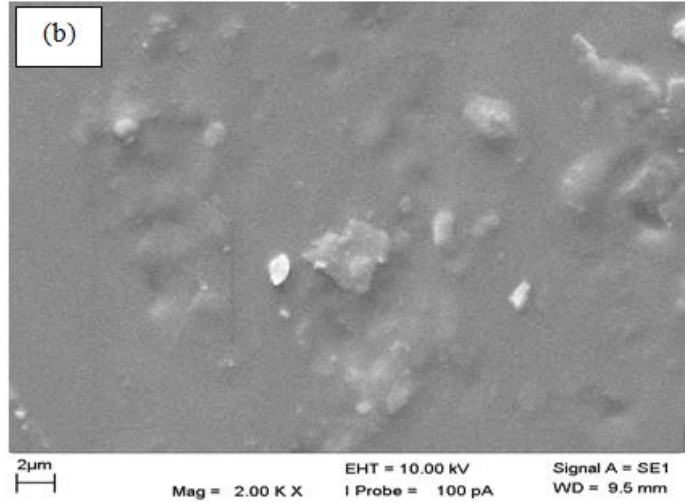
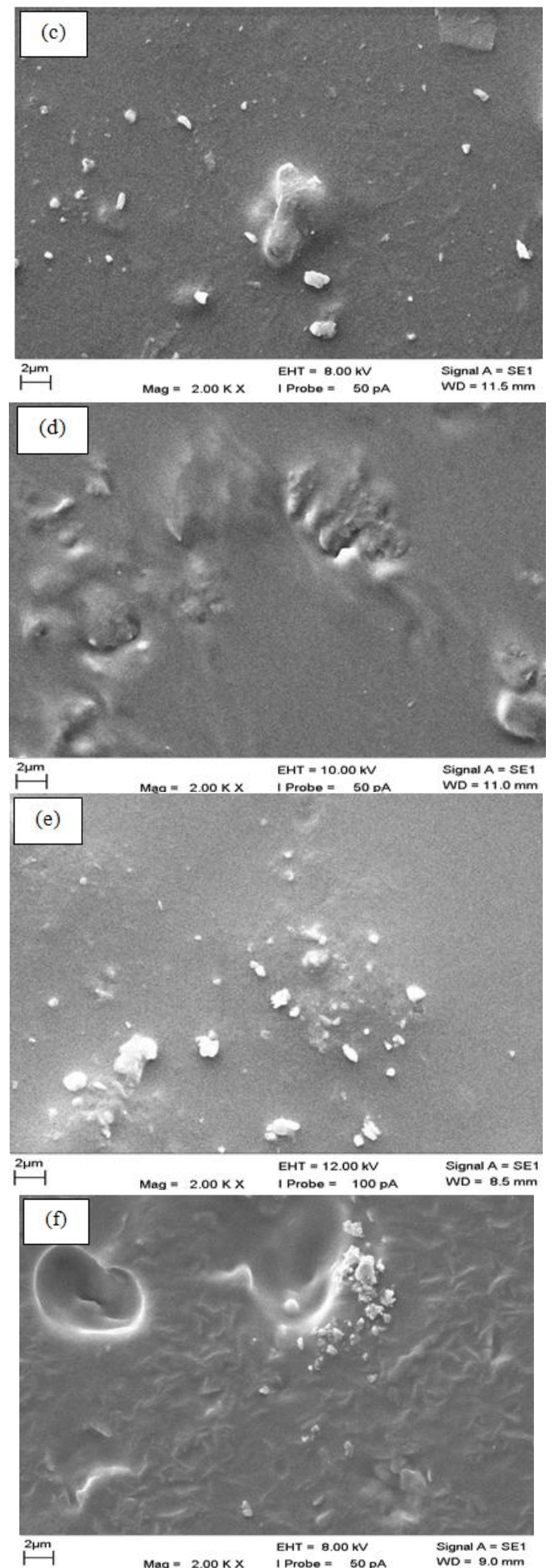

Fig. 1. SEM micrographs of fracture surface of (a) B30, (b) pristine PU, (c) $99.5 \% \mathrm{PU}+0.5 \% \mathrm{~B} 30$, (d) $99 \% \mathrm{PU}+1 \% \mathrm{~B} 30$, (e) $98 \% \mathrm{PU}+2 \% \mathrm{~B} 30$ and (f) $96 \% \mathrm{PU}+4 \% \mathrm{~B} 30$. 


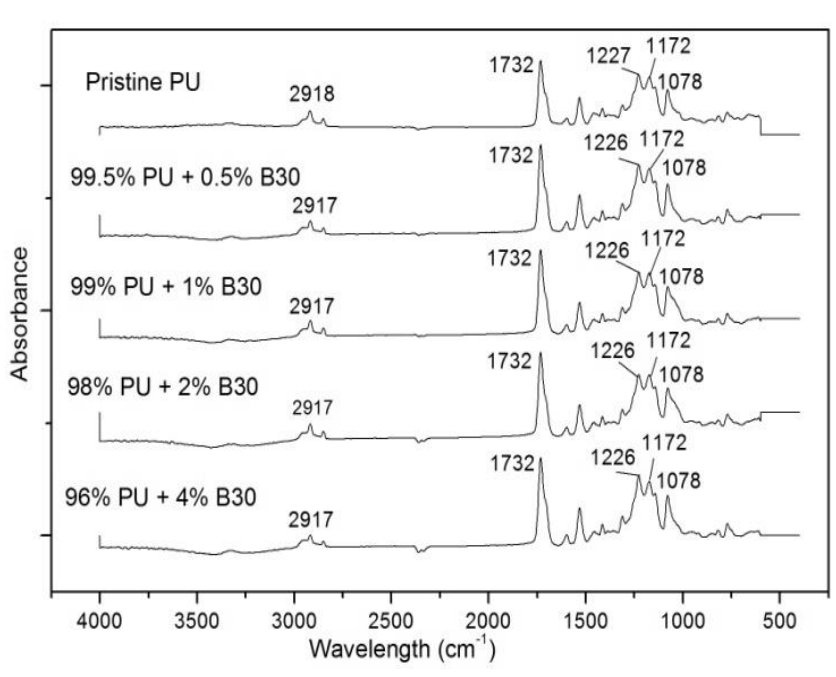

Fig. 2. The FTIR spectra of the different prepared samples.

At the peaks at $1732 \mathrm{~cm}^{-1},-\mathrm{C}=\mathrm{O}$ is being free and hydrogen bonding is formed [14]. So, this can be concluded that there is no chemical reaction involves in the PU and PU nanocomposite and this also shows the chemical structures for PU and PU nanocomposite has no any changes.

\section{B. Diffusivity Analysis}

The presence of $\mathrm{B} 30$ in PU reduces the water transmission to pass through the segmented structures in PU, besides lowering the permeability. The result of water permeability of all the series are shown in the Fig. 3. The observation for composition of $98 \% \mathrm{PU}+2 \% \mathrm{~B} 30$ illustrates a bit different for pressure at 3 bars of value $512 \mathrm{~s}$ that is higher that $96 \% \mathrm{PU}+4 \% \mathrm{~B} 30$. This is might be happened due to the agglomeration of B30 formed as in Fig. 1(e). The time consumed by every sample shows constantly increasing for pressure at 4 bars. That means the corporation of B30 in PU improved diffusivity behaviour even though there are a slight different for pressure at 3 bars. This can be explained by a factor of the impermeable nanofiller structure specifically increased the tortuosity of transport path [15]. Fig. 4 described the tortuosity of transport path in the PU nanocomposite. The figure illustrates tortuous path made by fillers retard the flow of water molecules to pass through the polymeric components.

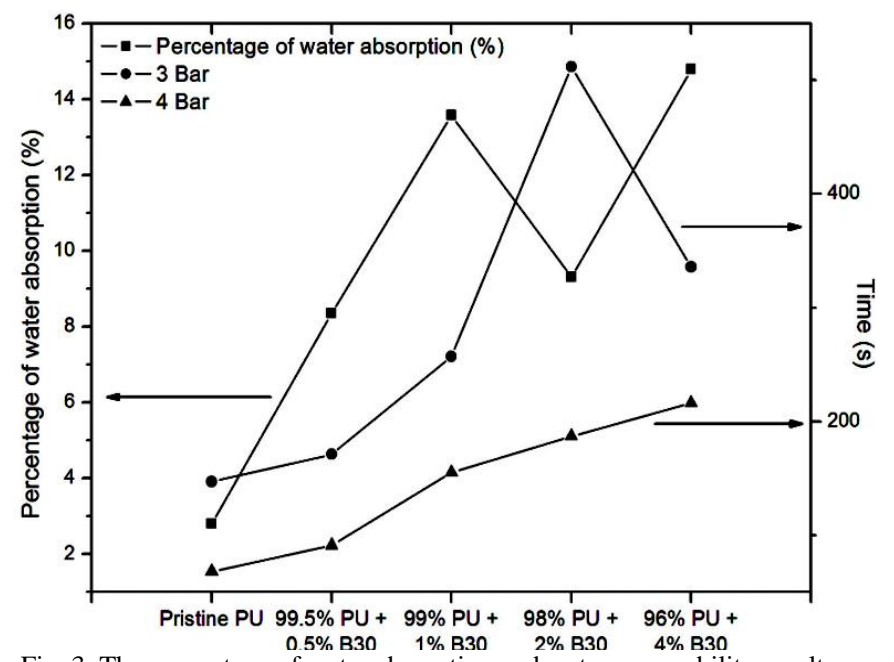

Fig. 3. The percentage of water absorption and water permeability result.

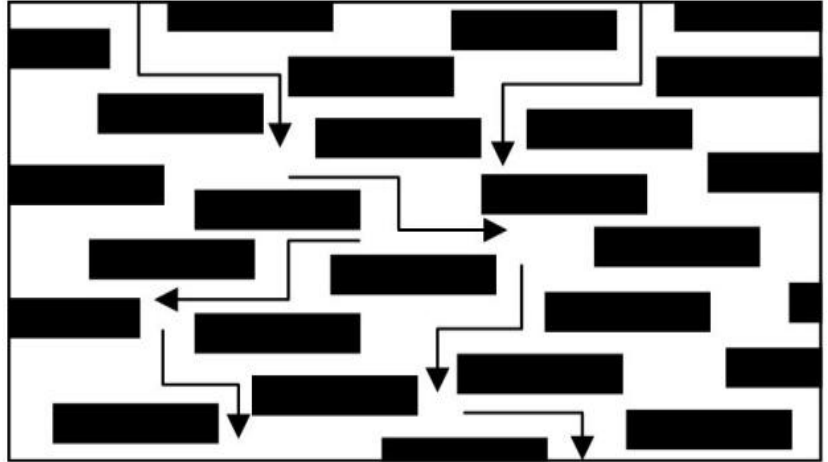

Fig. 4. The illustration of the water tortuosity of transport path through the polymer nanocomposite structure.

Water absorption was carried out according to ASTM D570 and the measurement was calculated by using Eq. (1).

$$
\text { Water absorption }(\%)=\left(W_{1}-W_{0}\right) / W_{0} \times 100 \%
$$

where $W_{1}$ represents the final weight after water absorption and $W_{0}$ the dried weight of the sample after drying. The result is demonstrated in Fig. 3. The polar of the percentage is increased persistently based on the result showed in Fig. 3 except for the series of $98 \% \mathrm{PU}+2 \% \mathrm{~B} 30$. The water absorption ratio increased with the content of the nanoclay. This reason probably contributed by the agglomerate and not even contribution while preparing the solution. The water absorption of the samples body is attributed by the water rich of the nanoclay. Other than that, the higher volume of nanoclay will increased the difficulty for water molecules to flow through the network of PU nanocomposite. [16], [17].

\section{CONCLUSION}

Incorporation of PU/B30 has proved that the improvement in diffusivity manner. PU nanocomposite has been synthesized with the nanometer scale silicate layers of organoclay completely in PU. Based on the SEM figure, there is agglomerates form in the samples. The PU segmented arrangement was not interfered by the presence of B30 regarding to there are no chemical structure changes as shown in FTIR result. PU nanocomposite imparts better water permeate properties as an efficient approach to promote the presence of B30. Additionally, PU nanocomposite based $\mathrm{B} 30$ has a special manner that possible to absorbs more water and this character may give an advantage in producing thermal building insulation material.

\section{ACKNOWLEDGEMENT}

The authors thank Universiti Malaysia Pahang (UMP) for the Ministry of Higher Education Grant RDU1203109 for the financial support along this research.

\section{REFERENCES}

[1] S. A. Al-Sanea and M. F. Zedan, "Optimum insulation thickness for building walls in a hot-dry climate," International Journal of Ambient Energy, vol. 23, no. 3, pp. 115 - 126, 2002.

[2] F. S. Pan, Q. L. Cheng, H. P. Jia, and Z. Y. Jiang, "Facile approach to polymer-inorganic nanocomposite membrane through a 
biomineralization-inspired process," Journal of Membrane Science, vol. 357, pp. 171-177, 2010.

[3] L. D. Tijing, M. T. G. Ruelo, A. Amarjargal, H. R. Pant, C.-H. Park, D. W. Kim, and C. S. Kim, "Antibacterial and superhydrophilic electr ospun polyurethane nanocomposite fibers containing tourmaline nano particles," Chemical Engineering Journal, vol. 197, pp. 41-48, 2012.

[4] J. H. Hong, E. H. Jeong, H. S. Lee, D. H. Baik, S. W. Seo, and J. H. Youk, "Electrospinning of polyurethane / organically modified mont morillonite nanocomposites," Journal of Polymer Science Part B: Pol ymer Physics, vol. 43, pp. 3171-3177, 2005.

[5] X. X. Cai, B. P. Li, Y. Pan, and G. Z. Wu, "Morphology evolution of immiscible polymer blends as directed by nanoparticle selfagglomeration," Polymer, vol. 53, pp. 259-266, 2012.

[6] S. Nataraj, K. Yang, and T. Aminabhavi, "Polyacrylonitrile-based nanofibers - a state of - the art review," Progress in Polymer Scienc,. 37, pp. 487-513, 2012

[7] T. K. Chen et. al., "Synthesis and characterization of novel segmented polyurethane/clay nanocomposites," Polymer, vol. 41, pp. $1345-1353,2000$.

[8] J. E. McBane, S. Sharifpoor, K. H. Cai, R. S. Labow, and J. P. Santerre, "Biodegradation and in vivo biocompatibility of a degradable, polar / hydrophobic / ionic polyurethane for tissue engineering applications," Biomaterials, vol. 32, pp. 6034-6044, 2011.

[9] D. K. Chattopadhyay and K. V. S. N. Raju, "Structural engineering of polyurethane coatings for high performance applications," Progress in Polymer Science, vol. 32, pp. 352-418, 2007.

[10] J. Jordan, K. Jacobb, R. Tannenbaumc, M. Sharafb, and I. Jasiukd, "Experimental trends in polymer nanocomposites," Materials Science and Engineering, vol. A-393, pp. 1-11, 2005.

[11] G. Bonilla, M. Martinez, A. M. Mendoza, and J. M. Widmaier, "Ternary interpenetrating networks of polyurethane-poly (methyl methacrylate)-silica: preparation by the sol-gel process and characterization of films," European Polymer Journal, vol. 42, pp. $2977-2986,2006$
[12] S. Q. Wei, Y. P. Bai, and L. Shao, "A novel approach to graft acrylates onto commercial silicones for release film fabrications by two-step emulsion synthesis," European Polymer Journal, vol. 44, pp. 2728-2736, 2008.

[13] H. T. Chiu, S. H. Chiu, and J. H. Wu, "Study on mechanical properties and intermolecular interaction of silicone rubber/polyurethane/epoxy blends," Journal of Applied Polymer Science, vol. 89, pp. 959-970, 2003

[14] K. H. Wei, T. K. Chen, and Y. I. Tien, "Synthesis and characterization of novel segmented polyurethane / clay nanocomposites," Polymer, vol. 41, pp. 1345-1353, 2000.

[15] S. Bruzaud, I. Zembouai, M. Kaci, A. Benhamida, Y. M. Corre, and Y. Grohens, "A study of morphological, thermal, rheological and barrier properties of poly (3-hydroxybutyrate-co-3-hydroxyvalerate) polylactide blends prepared by melt mixing," Polymer Testing, vol. 32, pp. 842-851, 2013.

[16] W. J. Ward, G. L. Gaines, M. M. Alger, and T. J. Stanley, "Gas barrier improvement using vermiculite and mica in polymer films," Journal of Membrane Science, vol. 55, pp. 173-180, 1991.

[17] K. Yano, A. Usuki, A. Okada, and T. Kurauchi, "Synthesis and properties of polyimide-clay hybrid," Journal of Polymer Science, Part A: Polymer Chemistry, vol. 31, pp. 2493-2498, 1993.

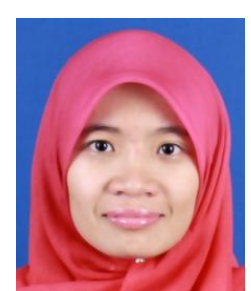

Norayuni Azizi was born in Teluk Intan, Perak on January 2, 1989. The author had studied in Sekolah Kebangsaan Sungai Tua Baharu, Selangor and was continue her high school in Sekolah Menengah Kebangsaan Gombak Setia, Selangor. Then, she entered matriculation level before her graduate as a Bachelor's degree holder in Chemical Engineering from Universiti Malaysia Pahang (UMP), Kuantan. Now, she is pursuing her Masters study at the same institution. She still studying in the same course as her previous degree, Masters in chemical engineering. 